\title{
Factors Affecting Entrepreneurial Intention Among Graduating Students at Debre Berhan University, Ethiopia
}

\author{
Melaku Desalegn Fantaye \\ Department of Management, Debre Berehan University, Debre Berehan, Ethiopia \\ Email address: \\ melakudesalegn77@gmail.com

\section{To cite this article:} \\ Melaku Desalegn Fantaye. Factors Affecting Entrepreneurial Intention Among Graduating Students at Debre Berhan University, Ethiopia. \\ Journal of Investment and Management. Vol. 8, No. 1, 2019, pp. 25-31. doi: 10.11648/j.jim.20190801.14
}

Received: January 22, 2019; Accepted: February 22, 2019; Published: March 12, 2019

\begin{abstract}
The present study is aimed at investigating factors affecting entrepreneurial intention among graduating students at Debre Berhan University. Little is known whether graduating students today are entrepreneurial. Notwithstanding the abundance of literature on entrepreneurship, factors affecting entrepreneurial intention among graduating students. Theory of planned behavior is adopted to specifically look at the effect of attitude towards entrepreneurship, perceived social norms and perceived behavioral control on entrepreneurial intention. In addition, entrepreneurship education and external environment are incorporated into the model as a moderator factors. The population used in this study was graduating students at Debreberhan University 2018/19 academic year. The Sampling techniques weremulti-stage sampling and purposive sampling with a total sample of 240 respondents. The data collection used questionnaires methods with 7likert scale, while the multiple linear regression analysis was used as an analytical technique by using SPSS 16.0. The findings show that the main effects, namely attitude towards entrepreneurship, perceived subjective norm and perceived behavioral control have positive relationship and significant effect on entrepreneurial intention among graduating students. It is also found that entrepreneurship education has appositive moderating effect on entrepreneurial intention among graduating students. It also suggeststhe future is owned by risk takers and not security seekers. The policy makers, universities and students play pivotal role in nurturing entrepreneurial spirit and bringing attitude change in students.
\end{abstract}

Keywords: Attitude Towards Entrepreneurship, Perceived Social Norms, Perceived Behavioral Control, Entrepreneurship Education, External Environment, Entrepreneurial Intention

\section{Introduction}

\subsection{Background of the Study}

Many scholars ask, either implicitly or explicitly, why anyone should study entrepreneurship. As many researches on the areas discloses, there is a strong positive correlations between entrepreneurship and economic growth in terms of creating a marvelous job opportunities both in urban and rural areas, stimulating creativity and innovation so as to transform technologies, knowledge and skills, expanding as well as ensuring firms survival and its sustainability. This in turn, increasingly made entrepreneurship emerged as one of the most popular research domain in academic circles [1].

Policymakers, economists, academics and even University students are fascinated by entrepreneurship [2]. This is mainly due to the importance of entrepreneurship in driving economic development and employment opportunities and overall competitiveness [3]. Moreover, the increasing unemployment condition annually becomes a fundamental issue for governments, businesses, and communities.

In Ethiopia self - employment becomes a more attractive and rewarding career option for the people and particularly for University students. One of the key factors explaining this unparalleled phenomenon is the fact that wages employment or 'secure' employment is no longer a guarantee especially in the public sector for university graduates [4]. Universities, by creating an entrepreneurial culture across campus, are expected to influence students' decision to creation businesses with its considerable influential factor on students.

An exponential interest in entrepreneurship studies has increased amongst both undergraduate and graduate students over the last decade [5]. Entrepreneurial Intention is the stepping stone for a comprehensive and stretched process of 
starting new ventures [6]. Intention is the most important factor that an individual is willing to entrepreneurship. Therefore, there is a need for more studies in the developing countries particularly in Ethiopia, because only few studies relating to this context are available. In addition, the Testing the theory will add to the existing literature of entrepreneurial intention. Thus, this study is intended to investigate the entrepreneurial intention among graduating students at DebreBerhan University, Ethiopia.

\subsection{Statement of the Problem}

In today's competitive job environment, total job opportunities are inevitably limited and thus one must compete to secure a job as supply of jobs is limited. As a result, many graduates are unable to get a job upon graduation. Students are now apparently searching for a business education that can equip them with the necessary entrepreneurial knowledge and skills to succeed in running businesses or to create a job from seizing existing entrepreneurial opportunities [2]. The future is owned by risk takers and not security seekers, as the more entrepreneurs seek security, the less security they have and the more they pursue opportunities, the more security that will be achieved.

The Government of Ethiopia put entrepreneurship education at the center of its policy agenda. The final goal of Growth and Transformation Plan -I was to transform Ethiopia into a middle-income country by 2025 . Among the many policies identified in the plan to achieve this goal there is the accelerated training of 10,000 trainers who in turn will provide capacity building on entrepreneurship. Similarly, the Growth and Transformation Plan -II recognizes the strategy importance of developing an entrepreneurial culture. Therefore, many universities and colleges in Ethiopiahas responded to this demand by introducing entrepreneurial courses and programsto students in an effort to promote entrepreneurship as well as a professional entrepreneurship career. On top of this, many dialogues, forums and training programs organized by educational institutions (Universities, Colleges, Institutes, schools, Ministry of Education, Management Institutes of Ethiopia) are all in favor of entrepreneurship development apart from being the subject taught at colleges and universities. Definitely, all these are being done with one major goal, namely to foster entrepreneurial spirit and expect attitude change in students, after undertaking entrepreneurial courses. Notwithstanding these efforts, a recent study found that entrepreneurship education and entrepreneurial activities are at their infant stage at Ethiopian universities. Lack of strategy, organizational capacity, innovative teaching methodologies, student de-motivation, and low cooperation with businesses are the main problems [7].

Entrepreneurial intention is the best predictors of entrepreneurial behaviors and activities [8]. Moreover, Entrepreneurial Intention is considered as the sapling of an entrepreneurial tree and first step towards the creation of new venture [6].

There is limited number of researches on the intentions of graduating students towards entrepreneurship at Ethiopian universities, Debre Berhan University particularly. This is a focal point for the present study. Keeping this background in mind, the main aim of this research is to investigate the factors affecting entrepreneurial intention among graduating students at Debre Berhan University.

\subsection{Objective of the Study}

\subsubsection{General Objective}

The overall aim of this study is to investigate the factors affecting entrepreneurial intention among graduating students at DebreBerhan University, Ethiopia.

\subsubsection{Specific Objective}

The specific objectives of the present study are the following:

(1) To assess the determinants of entrepreneurial intention among graduating students at Debre Berhan University.

(2) To examine the relationship between entrepreneurial attitudes, perceived social norms, perceived behavioral control, entrepreneurial education and external environment with entrepreneurial intention.

(3) To examine the extent of influence of entrepreneurial attitude, perceived social norms, perceived behavioral control, entrepreneurial education and external environment on entrepreneurial intention.

\subsection{Scope and Limitation of the Study}

The researcher believes that the findings of this study would have been more productive if it has been conducted at country or regional level. However, since the researcher is not full time researcher the time and financial constraints, it is out of the reach of the researcher to incorporate all the universities and colleges in country in this study. Due to this, the paper is limited to Debre Berhan University. Moreover, amongst many issues regarding entrepreneurship, this study focuses on the entrepreneurial intention among graduating students and its influencing factors only.

\subsection{Significance of the Study}

The study of factors affecting entrepreneurial intention among graduating students at Debre Berhan University is important in providing information that can enable to take effective measures by the universities and policy makers to improve the entrepreneurial spirit and culture. If measures are taken base on the research findings therewill be high opportunities in creatingsustainable job opportunity and improving the standard of livingof the graduates and community at large. Therefore, the outcome of the study is highlyuseful to identify innovative options and institutionalarrangements that would serve as an input and finally for fostering the intention of students towards entrepreneurial behaviour and activity. For policy makers in formulating entrepreneurshippolicy particularly onstudents it is highly important. 


\section{Theoretical Background}

\subsection{Entrepreneurial Intention}

It is believed that every human action is a result of intention, and intention implies a planned behavior [9]. Entrepreneurial intention can be also defined as a mental state that directs action toward self-employment rather than corporative employment [10].

\subsection{Factors Affecting Entrepreneurial Intention}

Theory of Planned Behavior propounded by Ajzenin1985, is identified as the most pervasive, robust, widely used and coherent approach in predicting the entrepreneurial intent [11]. Theory of Planned Behavior also described as one of the most recognized, reliablyvalidated, and prominent of the theories of entrepreneurial intention that offer the welldeveloped theory based [12]. The researcher considers attitudes towards entrepreneurship, perceived social norms and perceived behavior control as the main effects and entrepreneurship education and external environment as the moderator factor.

\subsubsection{Attitudes Towards Entrepreneurship}

Attitude is a readiness to react to certain objects in the environment as an appreciation of the object [13]. An object in the environment, in the study of these objects is entrepreneurship. People develop attitudes based on the beliefs they hold about the consequences of performing the behavior [14]. So the research hypothesis can be formulated as follows:

H.1: Attitudes towards entrepreneurship have a significant positive effect on entrepreneurial intention among graduating students

\subsubsection{Perceived Subjective Norms}

Perceived subjective norms are the views considered important by individuals who advise the individual to perform or not perform certain behaviors and motivation accompanied by a willingness to do or not do something that is considered important [15]. The subjective norms are positively related with entrepreneurial intentions [6]. In contrast of that, perceived social norms have little explanatory power for entrepreneurial intentions as mentioned by [16]. Therefore, the hypothesis can be formulated as:

H.2: Perceived subjective norms has a significantly positive effect on entrepreneurial intentionamong graduating students

\subsubsection{Perceived Behavioral Control}

Perceived behavioralcontrol refers to an individual's belief and confidence in his/her capability in performing as an entrepreneur and realizing control and success in entrepreneurial activity [17]. It is based on the notion that individuals usually choose to perform behaviors that they think they will be able to control and master [18]. Therefore, the hypothesis can be formulated as:
H.3: perceived behavioral control has a significantly positive effect on entrepreneurial intention among graduating students

\subsubsection{Entrepreneurship Education}

Entrepreneurship education is a conscious effort by individuals to increase knowledge about entrepreneurship [19]. Entrepreneurial education is among the fundamental factors that influences students' entrepreneurial intention [20, 21]. On a contrary, Entrepreneurship education has no changesin students' intention towards entrepreneurship after exposure to entrepreneurial education [22]. Thus; the researcher has set a hypothesis as:

H.4: Entrepreneurship education has a significantly positive effect on entrepreneurial intention among graduating students

\subsubsection{External Environment}

Environmental factors which influence entrepreneurial intentions are social, economic, political, infrastructure development and market emergence factors. The intention and market-oriented behaviours of an entrepreneur should also be influencedby the existing and anticipated economic and political infrastructure of thehome country [23]. Thus; the researcher has set a hypothesis as:

H.5: External environment has a significantly positive effect on entrepreneurial intention among graduating students

\section{Method}

\subsection{Research and Sample Design}

The design of the study that was used is descriptive and explanatory in nature. Descriptive research design was employed in order to discover the current situation of graduating students' entrepreneurial intention and to draw valid general conclusion regarding entrepreneurial intention, entrepreneurial attitude, perceived social norms, perceived behavioral control, entrepreneurial education and external environment. The study also employs explanatory study in order to discover the influence of entrepreneurial attitude, perceived social norms, perceived behavioral control, entrepreneurial education and external environment on entrepreneurial intention.

\subsection{Population and Sample Size Determination}

The population of the study was the graduating students of 2018/19 academic year at Debre Berhan University. Multistage sampling method was used to select the sample. First eight colleges were selected purposively from the total of ten colleges. Second, from those selected colleges, there are a total of 44 departments, 22 departments were selected again purposively. Finally, the researcher implementedstratified sampling technique to select 240 graduating studentsfrom the selecteddepartments. The sampling choice is coherent because of the students who learn entrepreneurship courses and have the experience of making a business plan are 
prospective entrepreneurs [24].

\subsection{Data Source and Data Collection Instruments}

This study mainly used primary data and secondary data. Primary data was collected directly from graduating students of 2018/19 academic year by using close ended questionnaire to be completed by sample respondent. The questionnaire was designed to capture all the necessary variables that are used to establish the determinants of entrepreneurial intention. Secondary data was collected from the different reports, published and unpublished materials.

\subsection{Measures}

In this study, the questionnaire contained six subscales: attitudes towards entrepreneurship, subjective norms, perceived behavioral control, and entrepreneurship education and program, external environment and entrepreneurial intention. The questions were adopted from Entrepreneurial Intention Questionnaire [11, 25]. Reliability and validity of the questionnaire were already verified to ensure that each pool of questions is related to same subject and each subject corresponds to the required measure [11]. The entrepreneurial intention questionnaireform contained 30 mandatory questions grouped into six main parts. The attitude towards entrepreneurship section included five items while the perceived social norms section had three items. The perceived behavioral control section consisted of six items. The entrepreneurship education section included six items. The external environment section contained four items and the entrepreneurial intention section consisted six items. All questions were measured using a 7-point Likert scales, starting from 1-strongly disagree to 7-strongly agree except for items pertaining to demographic background.

\subsection{Model Specification}

Multi-level regressions were conducted to determine the extent to which the independent variables affect the dependent variable. Multiple linear regression equation is as follows:

$\mathrm{Y}=\alpha+\beta 1 \mathrm{X} 1+\beta 2 \mathrm{X} 2+\beta 3 \mathrm{X} 3+\beta 4 \mathrm{X} 4+\beta 5 \mathrm{X} 5+\varepsilon$

Information:

$\mathrm{Y}=$ Intention entrepreneurship $\beta 1=$ regression coefficient attitude

$\mathrm{X} 1=$ Attitude $\beta 2=$ regression coefficient subjective norm

$\mathrm{X} 2=$ subjective norm $\beta 3=$ regression coefficient behavior control

$\mathrm{X} 3$ = Control Behavior $\beta 4=$ coefficient entrepreneurship education

$\mathrm{X} 4=$ entrepreneurship Education and $\operatorname{program} \beta 3=$ coefficient of external environment

X5 = external environment

$\varepsilon=$ Residual

\section{Results and Discussion}

\subsection{Results of Descriptive Statistics Analysis}

From the mean value in table 1 , it is found that graduate studentshave above moderate entrepreneurial intention. Regarding the attitude towards entrepreneurship, graduating students have high attitude towards entrepreneurship. Graduating students have less than moderate perceived social norms. Graduating students have moderate perceived behavioural control.

Regarding the moderating variables, graduating students rate moderately the presence entrepreneurship education while they rate the situation of external environment at moderate approximately.

Table 1. Results of the correlation analysis.

\begin{tabular}{|c|c|c|c|c|c|c|c|c|}
\hline \multirow{2}{*}{ EI } & \multirow{2}{*}{ Pear. Corr. } & Mean (st.dev.) & EI & ATE & PSN & PBC & E. EDU & E. ENV \\
\hline & & $3.62(1.396)$ & 1 & & & & & \\
\hline ATE & Pear. Corr. & $3.78(1.183)$ & $.741^{* *}$ & 1 & & & & \\
\hline PSN & Pear. Corr. & $2.58(1.297)$ & $.307^{* *}$ & $.283^{*}$ & 1 & & & \\
\hline $\mathrm{PBC}$ & Pear. Corr. & $3.38(1.215)$ & $.517^{* *}$ & .251 & .054 & 1 & & \\
\hline E. EDU & Pear. Corr. & $4.19(1.348)$ & $.641^{* *}$ & $.743^{*}$ & .354 & $.443^{*}$ & 1 & \\
\hline E. ENV & Pear. Corr. & $3.32(1.288)$ & $.103^{* *}$ & $.210^{*}$ & .108 & .163 & .079 & 1 \\
\hline
\end{tabular}

**. Correlation is significant at the 0.01 level (2-tailed).

*. Correlation is significant at the 0.05 level (2-tailed).

The correlation result is also shown in the table 1 . The result of this study reveals that there is a significant positive relationship between attitude towards entrepreneurship and entrepreneurial intention $(\beta=.741 ; p=0.000)$ at $1 \%$ level of significance. There is a positive but weak relationship between perceived social norms and entrepreneurial intention $(\beta=.307 ; p=0.000)$ at $1 \%$ level of significance. There is also a significant positive relationship between perceived behavioral control and entrepreneurial intention $(\beta=.517$; $p$ $=0.000)$ at $1 \%$ level of significance. Regarding the moderating variables, entrepreneurship education has significant positive relation with entrepreneurial intention $(\beta$
$=.640 ; \mathrm{p}=0.000)$ at $1 \%$ significance level, while external environment is insignificantly related $(\beta=.103 ; p=0.000)$ at $1 \%$ significance level.

\subsection{Results of Regression Analysis}

Multi-collinearity problem should be corrected when the correlation extent to be above $0.8[26]$. In our case, there is no correlation because there is no value that exceeds this value. The tolerance value which is also used to show the collinearity problem shows the absence of multicollinearity. That is all the tolerance values are notless than 0.10 . As a result, collinearity is not a problem. 
For this study multi-level regression analysis was applied. In the first model, only control variables were included and the main effects are added in the second model. Later on, moderating variables were included. The control variables are students' sex and department. The main effects are attitudes towards entrepreneurship, perceived social norms and perceived behavioral control. This study also used entrepreneurship education and external environment as moderating variable. The outcomes of the analysis reveals, the results were statistically significant because $\mathrm{F}=6.526, \mathrm{P}=0.008$ for model1, $\mathrm{F}=23.419, \mathrm{P}=0.000$ for model2, $\mathrm{F}=21.020$, $\mathrm{P}=0.000$ for model3. The main effects with the control variables alone explain entrepreneurial intention $47.2 \%$. In model 3 , after moderates are added, it explains about $58.8 \%$.

Table 2. Multi-level regression result.

\begin{tabular}{llll}
\hline Variables & Model 1 & Model 2 & Model 3 \\
\hline $\mathrm{N}$ & 240 & 240 & 240 \\
$\mathrm{SEX}$ & .029 & .038 & .064 \\
& $(.183)$ & $(.296)$ & $(.572)$ \\
Department & $.204^{* *}$ & $.230^{* *}$ & $.262^{* *}$ \\
& $(1.231)$ & $(1.358)$ & $(1.481)$ \\
ATE & - & $.583^{* * *}$ & $.508^{* * *}$ \\
& & $(7.683)$ & $(5.516)$ \\
PSN & - & $.359^{* * *}$ & $.257^{* * *}$ \\
& & $(3.132)$ & $(2.711)$ \\
PBC & - & $.538^{* * *}$ & $.438^{* * *}$ \\
& & $(3.965)$ & $(3.215)$ \\
E. EDU & - & - & $.472^{* * *}$ \\
& & & $(3.533)$ \\
E. ENV & - & - & .013 \\
& & & $(0.011)$ \\
Constant & $1.871^{* * *}$ & $1.014 * * *$ & $1.516^{* * *}$ \\
$\mathrm{R}^{2}$ & .233 & .632 & .766 \\
Adjusted $\mathrm{R}^{2}$ & .0761 & .472 & .588 \\
$\mathrm{~F}$ & 6.526 & 23.419 & 21.010 \\
\hline
\end{tabular}

$* * * \mathrm{p}<0.01 * * \mathrm{p}<0.05$
The result of model 1 indicates that students' sex has no influences on entrepreneurial intention. This implies being male or female is indifferent to wards having entrepreneurial intention. The students' field of study positively influences entrepreneurial intention. The result of model 2 also shows positive direct impact of students' attitude towards entrepreneurship, perceived social norms and perceived behavioural control on entrepreneurial intention. This indicates students with positive attitude, perceived social norms and perceived behavioural control can more to engage in opportunity discovery, evaluation, and exploitation.

Regarding model 3, this study also found that there is a positive moderation effect of entrepreneurial education betweenthe main effects and entrepreneurial intentionwhile external environment has no moderation effect betweenthe main effects and entrepreneurial intention. That is, entrepreneurship education helps graduating students towardsentrepreneurial intention, while theexternal environmentsdo not hinder students who have strong desire to be an entrepreneur because they assume problems and challenges as an opportunity to start a business.

\subsection{Hypothesis Testing}

Drawing on the previous literature, the researcher identifiesentrepreneurial attitude, perceived social norms, perceived behavioral control, entrepreneurial education and external environment as an independent variable and entrepreneurial intention as a dependent variable. Generally, the study offers a theoretical basis in the above linkage between the main and moderating effect of entrepreneurial education and external environments.

Table 3. Hypotheses testing.

\begin{tabular}{|c|c|c|}
\hline HRelationship & B & Result \\
\hline H1 There is a positive influence of attitude towards entrepreneurship on entrepreneurial intention among graduating students & $.508 * * *$ & Supported \\
\hline $\mathrm{H} 2$ There is a positive influence of perceived social norms on entrepreneurial intention among graduating students & $.257 * * *$ & Supported \\
\hline H3 There is a positive influence of perceived behavioral control on entrepreneurial intention among graduating students & $.438 * * *$ & Supported \\
\hline H4 There is a positive influence of entrepreneurship education on entrepreneurial intention among graduating students. & $.472 * * *$ & Supported \\
\hline H5 There is a positive influence of external environment on entrep & $.013 * * *$ & Notsupported \\
\hline
\end{tabular}

$* * * \mathrm{p}<0.01$

\section{Conclusion}

The adoption of entrepreneurial intention among graduating students depends on their attitude towards entrepreneurship, perceived social norms, perceived behavioral control, entrepreneurship education and external environment. This study makes contribution to the fields of entrepreneurial intention and their influencing factors through a comprehensive review of literature and empirical study available in the area. That is, the moderating effects of both entrepreneurship education and external environment on the entrepreneurial intention are tasted.

Thus, this study supports attitude towards entrepreneurship, perceived social norms, perceived behavioral control has positive relationship and significantly affecting entrepreneurial intention among graduating students. Entrepreneurship education has a positive moderating effect on entrepreneurship intention but external environment has no moderating effect on entrepreneurship intention among graduating students.

\section{Recommendation}

By having the above conclusions, the researcher provided the following implications to the government, policy makers, universities and students. As the finding of the study 
indicates, the policy makers should improve on the policy of developing entrepreneurial development programs by giving consideration to facilitate on how to access resource and by removing unnecessary conditions that hinders the development of entrepreneurs. Universities should contribute beyond offering entrepreneurship courses rather the introduction of targeted entrepreneurship programs, internships, creation of business incubators, creation of industry and university partnerships can be very productive in nurturing the entrepreneurial intention among students. Finally, the future is owned by risk takers and not security seekers. There for, students need to be self-motivated to read books, discuss with family and successful entrepreneurs, gain experience, and entrepreneurship training programand look at the business in the local or international market and conduct market research so that interest will be able to grow business opportunities and develop a sense of confidence in the ability to manage the business.

\section{References}

[1] Lee, S. M., D. Chang, et al. (2005). "Impact of entrepreneurship education: A comparative study of the U.S. and Korea." International Entrepreneurship and Management Journal 1: 27-43.

[2] Henry, B. (2003). "Entrepreneurship education in Kenya: A reality or plodding on?" The First International Entrepreneurship Conference, 23-24 April Kenya.

[3] Meyer, N. (2017). "South Africa's youth unemployment dilemma: Whose baby is it anyway?" Journal of Economics and Behavioral Studies, 9(1), 56-68.

[4] Postigo, S., D. Iacobucci, et al. (2006). "Undergraduates students as a source of potential entrepreneurs: A comparative study between Italy and Argentina. International entrepreneurship education: Issues and newness." A. Fayolle and H. Klandt. Cheltenham, UK, Edward Elgar Publishing, Inc.

[5] Solomon, G. T., K. M. Weaver, et al. (2005). "Pedagogical methods of teaching entrepreneurship: An historical perspective. Keystones of entrepreneurship knowledge." $R$. $V$. D. Horst, King-Kauanui, S. \& Duffy, S. Malden, MA, Blackwell Publishing Inc.

[6] Karimi, S., Biemans, H. J. A., NaderiMahdei, K., Lans, T., Chizari, M., \& Mulder, M. (2015). "Testing the relationship between personality characteristics, contextual factors and entrepreneurial intentions in a developing country: personality, context and intentions." International Journal of Psychology, $n / a-n / a$.

[7] Mudde, H. L., Gerba, D. T., \&Chekol, A. D. (2015). "Entrepreneurship Education in Ethiopian universities: Institutional assessment." Synthesis Report No. 2015/01, NICHE project 'University Leadership and Management Capacity Development'.

[8] Aloulou, W. J. (2016). "Predicting entrepreneurial intentions of final year Saudi university business students by applying the theory of planned behavior." Journal of Small Business and Enterprise Development, 23(4), 1142-1164.
[9] Uygun, R., \&Kasimoglu, M. (2013). "The emergence of entrepreneurial intentions in indigenous entrepreneurs: the role of personal background on the antecedents of intentions." International Journal of Business and Management, 8(5), 2440.

[10] Souitaris, V., S. Zerbinati, and A. Al-Laham. (2007). "Do entrepreneurship programmes raise entrepreneurial intention of science and engineering students? The effect of learning, inspiration and resources" Journal of Business Venturing. 22 (4): 566-591.

[11] Liñán, F. and Chen, Y. W. (2009). "Development and crosscultural application of a specific instrument to measure entrepreneurial intentions." EntrepreneurshipTheory and Practice, 33 (3): 593-617.

[12] Owoseni, O. O., \&Akambi, P. A. (2010). "Entrepreneurial Intentions: A Theoretical Framework." Journal of Management and Corporate Governance, 2(4), 132-148.

[13] Efendi, F., Makhfudli. (2009). "Keperawatan Kesehatan Komunitas Teoridan Praktikdalam Keperawatan. Jakarta:" Salemba Medika.

[14] Schlaegel, C., \& Koenig, M. (2014). "Determinants of Entrepreneurial Intent: A Meta-Analytic Test and Integration of Competing Models. Entrepreneurship Theory and Practice", 38(2), 291-332.

[15] Wedayanti, N. P., danGiantari, I. (2016). "Peran Pendidikan Kewirausahaan Dalam Memediasi Pengaruh Norma Subyektif Terhadap Niat Berwirausaha.” E-Jurnal Manajemen Universitas Udayana. Vol. 5 No. 1. pp. 533-560.

[16] Ridder, A. (2008). "The influence of perceived social norms on entrepreneurial intentions"(Unpublished Master thesis), University of Twente, Netherlands

[17] Ajzen I.(2002). "Perceived behavioural control, self-efficacy, locus of control, and the theory of planned behaviour." Journal of Applied Social Psychology, 32(4), 665- 683.

[18] Moriano, J. A., Gorgievski, M., Laguna, M., Stephan, U. and Zarafshani, K. (2012). "A cross-cultural approach to understanding entrepreneurial intention." Journal of Career Development, 39: 162-85, doi: 10.1177/0894845310384481.

[19] Gerba. D. T. (2012). "Impact of entrepreneurship education on entrepreneurial intentions of business and engineering students in Ethiopia." African Journal of Economic and Management Studies. Vol. 3 No. 2. pp. 258-277.

[20] Adelaja\&Arshad (2016). "Does entrepreneurial intention differ between public and private universities' students?" International Journal of Entrepreneurship and Small \& Medium Enterprise, 3, 133-110.

[21] Karabulut, A. T. (2014). "Entrepreneurial career intentions of alumni: A study in a Turkish Foundation University." International Journal of Business and Management, 9(2), 30.

[22] Barral, M. R. M., Ribeiro, F. G., \& Canever, M. D. (2018). "Influence of the university environment in the entrepreneurial intention in public and private universities." RAUSP Management Journal, 53(1), 122-133.

[23] Lüthje, C., \& Franke, N. (2003). "The 'making' of an entrepreneur: testing a model of entrepreneurial intent among engineering students at MIT. R\&D Management,"33(2), 135-147 
[24] Chen, L. (2013). "IT Entrepreneurial Intention among College Students: An Empirical Study." Journal of Information Systems Education, 24(3), 233-243.

[25] Ajzen I. (1991).“The Theory of Planned Behaviour", Organizational Behaviour and Human Decision Processes, 50, 179-211\&2001).
[26] Cooper \& Schindler (2009). "Business research methods, (9th ed,).” McGraw-Hill: Irwin. 